\title{
ORIENTACJA NA TESTY W SZKOLNICTWIE WSPÓŁCZESNYM - KONTROWERSJE IDEOLOGICZNE I PEDAGOGICZNE
}

\begin{abstract}
Gromkowska-Melosik Agnieszka, Orientacja na testy w szkolnictwie wspótczesnym - kontrowersje ideologiczne i pedagogiczne [Tests Oriented Education in Contemporary Schooling - Ideological and Pedagogical Controversies]. Studia Edukacyjne nr 36, 2015, Poznań 2015, pp. 19-32. Adam Mickiewicz University Press. ISBN 978-83-232-2958-2. ISSN 1233-6688. DOI: 10.14746/se.2015.36.2

The purpose of the article is reconstruction of the problem of ideological and social controversies surrounding the growing importance of the tests in determining the boundaries of contemporary neoliberal school reality. There is no doubt that in recent years the focus of the test-driven policies applied in the context of both formal and social criteria for evaluating students and schools has shifted decisively towards tangible results associated with the tests results. You can even tell that the phenomenon of "testing obsession" has dominated everyday life of the school and the identity of the students and has replaced student-centering learning. The author of the article considers these problems against the background of theory and reality.
\end{abstract}

Key words: tests, neoliberalism, culture of testing, student-centered learning, test-driven policies

Celem mojego tekstu jest - z konieczności nieco fragmentaryczna - rekonstrukcja problemu ideologicznych oraz społecznych kontrowersji wokół rosnącego znaczenia testów w wyznaczaniu granic współczesnej neoliberalnej rzeczywistości szkolnej. Nie ulega wątpliwości, że w ostatnim okresie punkt ciężkości w zakresie stosowanych, zarówno w kontekście formalnym jak i społecznym, kryteriów oceny uczniów oraz szkół przesunął się zdecydowanie $\mathrm{w}$ kierunku wymiernych rezultatów związanych $\mathrm{z}$ wynikami testów. Można wręcz mówić, i jestem o tym przekonana, o zjawisku „testologii”, które zdominowało codzienność szkoły i tożsamość uczniów. 
Wspomniana dominacja rzeczywistości szkolnej oraz świadomości (i szerzej - biografii) uczniów przez wspomnianą logikę testów nie może pozostać bez konsekwencji. Warto odwołać się $\mathrm{w}$ tym miejscu do pewnych wątków, przeprowadzanej przez teoretyków i badaczy edukacji, krytyki absolutyzowania roli testów w edukacji. I tak, w nurcie krytyki wzrastającego znaczenia testów eksponuje się ich redukcjonistyczny charakter. Richard P. Phelps stwierdza wymownie: „akademickie osiągnięcia są [przecież AG-M] tylko jednym $z$ wielu i to zdecydowanie nie najbardziej znaczącym celem, które [nauczyciele] realizują $\mathrm{w}$ trakcie edukacji"1, a podporządkowanie rzeczywistości szkolnej testom powoduje, że inne cele są w coraz większym stopniu zaniedbywane. Na aspekt redukcjonizmu testów wskazują w swojej krytycznej książce Philip Harris, Bruce M. Smith i Joan Harris. Autorzy ci podkreślają, że testy w żaden sposób nie są w stanie zmierzyć takich „jakości" inherentnie związanych z procesem kształcenia, jak: kreatywność, krytyczne myślenie, ciekawość, poczucie odpowiedzialności, entuzjazm, empatia, przywództwo, wewnętrzne zintegrowanie i jeszcze wielu innych ${ }^{2}$ (czy - dodam od siebie - świadome obywatelstwo). A jeżeli tego nie mierzą, to nauczyciele nie orientują się na rozwijanie tych cech.

Odwołując się do rozważań Zbyszka Melosika, można raz jeszcze stwierdzić, że

konsekwencją tego jest zmiana aspiracji i ambicji uczniów, nauczycieli i władz szkolnych na różnym poziomie - z kształtowania/kształcenia mądrych i krytycznych uczniów na rzecz przygotowania "rozwiązywaczy” testów. I w tym wypadku władza ministerialna wyznacza kryteria i standardy, dokonując nieskończonej liczby klasyfikacji i wartościujących porównań3 ${ }^{3}$.

Można więc skonstatować, za Michele S. Moses i Michaelem J. Nanną, że wyniki testów dostarczają uproszczonego obrazu stanu procesu nauczania i uczenia się ${ }^{4}$. Orientacja na testy prowadzi zatem do wykształcenia, zarówno wśród uczniów jak i nauczycieli, postawy „powierzchownego zaanga-

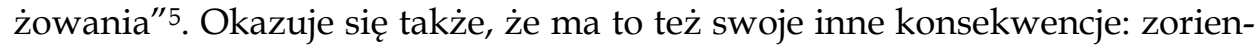
towani na przygotowanie swoich uczniów do rozwiązywania testów nauczyciele obniżają wobec nich wymagania w innych obszarach kształce-

${ }^{1}$ R.P. Phelps, Kill the Messenger. The War on Standardized Testing, New Jersey 2009, s. 21.

2 P. Harris, B.M. Smith, J.J. Harris, The Myths of Standarized Tests. Why They Don't Tell You What You Think They Do, Lanham - Boudler - New York - Toronto - Plymouth 2011, s. 35.

${ }^{3}$ Z. Melosik, Kultura popularna i tożsamość młodzieży. W niewoli władzy i wolności, Kraków 2013, s. 396.

${ }^{4}$ M.S. Moses, M.J. Nanna, The Testing Culture and the Persistence of High Stakes Testing Reforms, Education and Culture, 2007, 23, 1, s. 63.

${ }^{5}$ P. Harris, B.M. Smith, J.J. Harris, The Myths of Standarized Tests, s. 35. 
nia - tych, które nie są testowane, jak na przykład muzyka czy plastyka ${ }^{6}$. Powszechne wykorzystywanie standardyzowanych testów prowadzi do rezygnacji przez nauczycieli z metod nauczania zorientowanych na rozwój ucznia na rzecz metod zorientowanych na przekazywanie formalnej wiedzy i kompetencji w zakresie rozwiązywania testów. W konsekwencji, z czasem nauczyciel pozbywa się tych własnych kompetencji pedagogicznych i nauczycielskich, które nabył w trakcie swojej własnej edukacji, bowiem nie są mu one potrzebne7. Traci też szacunek dla samego siebie, jako że "standardyzowane testy stanowią afront $\mathrm{w}$ stosunku do profesjonalizmu nauczyciela; implikują bowiem, że nie możemy mu ufać" - w zakresie dokonywania przez nich oceny uczniów zastępowani są przez zewnętrznych ekspertów wytwarzających testy ${ }^{8}$. Odpowiedzialność nauczyciela wzrasta, bowiem to jego wini się za złe wyniki w testach jego uczniów, jednakże jego autorytet maleje (bowiem - poza przygotowaniem do testów - ma niewiele innej przestrzeni edukacyjnego działania) ${ }^{9}$. Warto $\mathrm{w}$ tym miejscu przedstawić krótko krytyczne poglądy wobec testów Diane Ravitch (do niedawna jeszcze czołowej amerykańskiej konserwatystki), która pisze; "testy są konieczne i pomocne, lecz testy muszą być uzupełniane oceną człowieka“. Przeciwstawia się ona "definiowaniu istoty edukacji jedynie przez to, co można mierzyć"10, bowiem "szkoły są odpowiedzialne za kształtowanie charakteru i rozwijanie otwartych umysłów w zdrowych ciałach oraz wychowywanie obywateli dla naszej demokracji"11. Autorka ta krytykuje również stosowanie wobec nauczycieli nagród za lepsze wyniki testów ich uczniów, jak również ignorowanie tych nauczycieli, którzy „kształtują w swoich uczniach pełne pasji zainteresowania historią, naukami przyrodniczymi, sztuką, literaturą i językami obcymi“ - w oderwaniu od testów ${ }^{12}$. Z drugiej strony trzeba w tym miejscu stwierdzić, że zwolennicy testów eksponują fakt, iż alternatywny wobec nich system - oparty na ocenach uczniów dokonywanych przez nauczycieli - nie jest wcale bardziej wiarygodny. Są one często subiektywne, a wpływ na nie mają takie niezwiązane $z$ kognitywnymi kompetencjami uczniów czynniki, jak ich wykazywany na lekcjach entuzjazm oraz ogólna postawa wobec przedmiotu i nauczyciela ${ }^{13}$.

${ }^{6}$ R.P. Phelps, Kill the Messenger, s. 291.

7 Tamże, s. 289.

8 Tamże, s. 81.

${ }^{9}$ E. Shohany, The Power of Tests. A Crtical Perspective on the Uses of Language Tests, Harlow 2001, s. 107.

${ }^{10}$ D. Ravitch, The Death and Life of the Great American School System. How Testing and Choice Are Undermining Education, New York 2010, s. 166.

11 Tamże, s. 167.

12 Tamże, s. 194.

${ }^{13}$ R.P. Phelps, Kill the Messenger, s. 278-279. 
Podobny sposób myślenia prezentuje Elana Shohamy, która wyróżnia szereg destruktywnych kontekstów oddziaływania testów na rzeczywistość szkolną. I tak, jej zdaniem fakt, iż testy przekształciły się ze środków w cele powoduje „zawężenie" procesu kształcenia i nadanie mu instrumentalnego charakteru, przy czym język nauczania (stanowiący integralną część metodologii nauczania) staje się tożsamy z , ,językiem [rozwiązywania - AG-M] testu". Nauczyciele stosują redukcjonistyczne podejście do programu szkolnego, realizując przede wszystkim te jego części, które mogą potencjalnie podlegać testowaniu, przy czym w sposób szczególny minimalizuje się rozwijanie kompetencji uczniów w zakresie formułowania dłuższych wypowiedzi pisemnych ${ }^{14}$. Tak więc, treść programu szkolnego i sposoby nauczania są „przetwarzane w kategorie typowe dla testów” ${ }^{15}$. Z kolei, u uczniów orientacja na testy prowadzi do rozwijania metod myślenia ukierunkowanych na „szybkie dopasowanie" oraz na poszukiwanie "natychmiastowych rozwiązań, które pomijają skomplikowaną istotę przedmiotu wiedzy"16. Zdaniem Petera Sacksa, "tradycyjne testy wzmacniają pasywne zorientowanie na uczenie się na pamięć faktów i formul, co stanowi przeciwieństwo krytycznego myślenia"17. Uznaje on przy tym, że „wymagające pospiesznego wypełniania testy wielokrotnego wyboru są same $\mathrm{w}$ sobie potężnym bodźcem na rzecz sfragmentaryzowanego i powierzchownego uczenia się"18. Poza tym, zdaniem Elany Shohamy, uczniowie zaczynają postrzegać naukę szkolną nie jako wartość samą w sobie, ale w kontekście liczby punktów, które należy uzyskać (i korzyści z tego wynikających) ${ }^{19}$. Można w tym miejscu przywołać zasadne uwagi Zbyszka Melosika, których istotą jest teza o projektowaniu przez uczniów podejścia "testologicznego", w które socjalizowani są w szkole na inne dziedziny ich życia. Autor ten pisze w sposób następujący:

Testy wyrabiają u uczniów taki sposób myślenia, który skoncentrowany jest na rozwiązywaniu zadań testowych. Można w tym kontekście zadać dość dramatyczne pytania: $\mathrm{w}$ jakim stopniu taki sposób myślenia przenoszony jest przez ludzi do życia społecznego? W jakim stopniu rzeczywistość staje się dla młodych ludzi zbiorem pytań testowych, przy czym w przypadku każdego z nich należy znaleźć (zgadnąć?) właściwą odpowiedź? W jakim wreszcie stopniu młodzi ludzie zaczynają i swoją tożsamość postrzegać jako zbiór pytań testowych? Czy nie mamy tu do czynienia

${ }^{14}$ E. Shohamy, The Power of Tests, s. 110-111.

15 Tamże, s. 112.

16 Tamże.

17 P. Sacks, Standardized minds: The High Price of America's Testing Culture and what We Can Do to Change It, New York 1999, s. 9.

18 Tamże.

${ }^{19}$ E. Shohamy, The Power of Tests, s. 107. 
z rekonstrukcją stosunku do samych siebie? Czy refleksyjna samoświadomość człowieka, odnosząca się do całości jego życia w przebiegu biografii nie została przekształcona na wzór testu, który należy rozwiązać? Czy pytania „kim chcę być?” i „jak chcę żyć?" nie są rekonstruowane w serię oddzielnych, niekiedy w ogóle ze sobą niezwiązanych zadań testowych?20

Elana Shohamy, wykorzystująca koncepcję Michaela Foucaulta, twierdzi, że powszechne posługiwanie się testami stanowi formę praktykowania normalizującej władzy nad tożsamością uczniów, przy czym „testy składają się z rytuałów i ceremonii, wraz z narzucaniem [szczególnej wersji - AG-M] prawdy, a wszystko to w imię obiektywności"21. Autorka ta twierdzi, za George'em Madausem, że "testy stanowią skonstruowane w sposób naukowy narzędzie, które (...) było wykorzystywane jako mechanizm kontroli i władzy, głęboko zakorzeniony zarówno w sferze edukacji, jak i rządu oraz biznesu" 22. W swojej rekonstrukcji poglądów F. Allana Hansona pisze ona, że "testy stały się instytucjami społecznymi, które działają w swoim własnym imieniu, [a ich] istnienie uznawane jest za całkowicie naturalne" 23 . Zdaniem tej samej autorki, testy stanowią jedną z metod "utrzymywania porządku społecznego" i "symbolicznej dominacji”, potwierdzając istniejące podziały klasowe ${ }^{24}$. Politycy oświatowi postrzegają testy $\mathrm{w}$ kategoriach „magicznych" - mają one niemal automatycznie zwiększyć jakość kształcenia i przynieść edukacji doskonałość25.

Szczególne znaczenie mają, jak to ujmują Robert Kirkpatrick i Yuebing Zang, takie testy, które odnoszą się do „wielkiej stawki”, bowiem determinują losy uczniów, niekiedy wręcz w kontekście całożyciowym. Decydują one bowiem o dalszych szansach edukacyjnych uczniów, przy czym ich skutki mogą być natychmiastowe (np. dostanie się do prestiżowej uczelni lub szkoły średniej) lub opóźnione (ten drugi przypadek odnosi się np. do ich wpływu na umieszczanie poszczególnych uczniów na różnych „ścieżkach kształcenia", prowadzących do odmiennych karier edukacyjnych) ${ }^{26}$. Testy, opierając się na zasadzie hipermierzalności rezultatów, prowadzą do uniformizacji i standaryzacji zarówno uczniów, jak i procesu kształcenia ${ }^{27}$. $\mathrm{Z}$ drugiej strony, przyczyniają się też bez wątpienia do pogłębienia atmosfe-

20 Z. Melosik, Kultura popularna i tożsamość młodzieży, s. 350.

${ }^{21}$ E. Shoamy, The Power of Test, s. 17.

22 Por. tamże, s. 18.

23 Tamże.

24 Tamże, s. 118 i 120.

25 Tamże, s. 126.

${ }_{26}$ R. Kirkpatrick, Y. Zang, The Negative Influences of Exam-Oriented Education on Chinese High School Students: Backwash from Clasroom to Child, Language Testing in Asia, 2011, 1, 3, s. 37.

27 Tamże. 
ry rywalizacji wśród uczniów, a także wzmagają indywidualizm i redukują gotowość do współpracy oraz pracy zespołowej.

Inny kontekst krytyki testów wiąże się z ich rolą w pogłębianiu nierówności społecznych. Zdaniem wielu krytyków, redukują ideę równości w edukacji do jej formalnych aspektów ${ }^{28}$. W praktyce testy wpisują się znakomicie w liberalną ideologię merytokracji, która eksponując rolę jednostki i jej indywidualnych osiągnięć, ukrywa istniejące $\mathrm{w}$ społeczeństwie strukturalne nierówności. Przy tym,

słabe wyniki osiągane $\mathrm{w}$ standaryzowanych testach przez osoby wywodzące się z klasy robotniczej, o innym niż biały kolorze skóry lub przez przedstawicieli pewnych grup emigrantów są w sposób bezpośredni (...) łączone $\mathrm{z}$ niepowodzeniem konkretnych jednostek 29

(a nie z nieuprzywilejowaniem grupy społecznej do której należą). Dzieje się tak tym bardziej, że statystyczna logika standaryzowanych testów z góry zakłada porażkę części uczniów ${ }^{30}$ (co wpływa nie tylko na poczucie własnej wartości tychże - badania wykazują, że rola testów jest w znaczący sposób absolutyzowana; jak ujmuje to S.R. Anderson: „wielu rodziców utożsamia wyniki testów swoich dzieci (...) z sukcesem rodziny"31).

Najbardziej chyba ekstremalnego przykładu orientacji na egzaminy testowe dostarczają kraje Dalekiego Wschodu - szczególnie na poziomie szkolnictwa średniego. I tak, w Japonii koncentracja działalności szkół na tym celu kształtuje - w kontekście socjalizacyjno-selekcyjnym - jednostki o określonej tożsamości. S. Yoneyama przywołuje tutaj pogląd Takeuchi, że u uczniów „nieustannie wystawianych na współzawodnictwo i skoncentrowanych na wygranej (...) rozwija się «biurokratyczny duch» w «posłusznym ciele»"32. W konsekwencji, jak pisze krytycznie Yoneyama, supermerytokracja wytwarza jednostki o bardzo jednoznacznym (de facto - mało skomplikowanym) charakterze, który dostosowuje się do potrzeb korporacyjnej Japonii, wytwarza ona też osobowość akceptującą „kierowanie przez program odgórny” lub „oczekującą na instrukcje”33 (japońskie szkoły średnie oskarżane są też przez zachodnich krytyków o to, iż - przyswajający sobie miliony faktów i formułek - uczniowie traktowani są w nich jak automaty, zaś

${ }^{28}$ Por. dyskusję w: M.S. Moses, M.J. Nanna, The Testing Culture, s. 65-67.

${ }^{29} \mathrm{~W}$. Au, Hiding behind high-stakes testing: Meritocracy, objectivity and inequality in U.S. education, Education Journal: Comparative Perspectives, 2013, 12, 2, s. 13.

${ }^{30}$ R. Kirkpatrick, Y. Zang, The Negative Influences, s. 14.

31 Podaję za: M.S. Moses, M.J. Nanna, The Testing Culture, s. 63.

32 Por. S. Yoneyama, The Japanese High School: Silence and Resistance, London 1999, s. 53.

33 Tamże. 
proces kształcenia jest $\mathrm{w}$ nich „ekstremalnie sformalizowany, surowy i autokratyczny" ${ }^{\prime 4}$ ).

Innym przykładem takiego podejścia jest edukacja w Singapurze, w którym biografia szkolna uczniów składa się z uczestnictwa w kolejnych etapach selekcji/rywalizacji, w trakcie których dokonuje się podziału na zwycięzców i przegranych - na podstawie wyników testów oraz ocen szkolnych ${ }^{35}$. Cechuje ją hiperkonkurencyjność36. Standaryzowane testy egzaminacyjne stanowią istotę singapurskiej merytokracji; postrzegane są one jako obiektywne narzędzie służące „mierzeniu” zarówno talentu, jak i włożonego w naukę wysiłku ${ }^{37}$. Konkurencja między uczniami zaczyna się w Singapurze już od najwcześniejszych lat życia, a singapurska szkoła podstawowa nazywana jest wręcz gigantyczną "kognitywną maszyną": testującą, segregującą, przesiewającą i dzielącą uczniów na grupy - wyodrębnione ze względu na wyniki osiągane $\mathrm{w}$ testach ${ }^{38}$ (występuje przy tym także zjawisko stratyfikowania singapurskich szkół podstawowych w różnego typu rankingach ${ }^{39}$ ). Proces ten kontynuowany jest na kolejnych szczeblach edukacji, $\mathrm{w}$ których wyniki testów wyznaczają losy edukacyjne i społeczno-zawodowe jednostki.

Warto w tym miejscu dodać, że w dokumencie programowym Singapurskiej Partii Demokratycznej (Singapore Democratic Party) - ugrupowania opozycyjnego względem frakcji rządzącej - widnieje zaniechanie segregowania dzieci ze względu na uzyskane przez nie wyniki egzaminów ${ }^{40}$. Uznano, że istniejący system niszczy kreatywność i niezależne myślenie. Produkuje ludzi, których umysły są "zamknięte w pudełkach" i zorientowane przede wszystkim na zapamiętywanie faktów ${ }^{41}$. Niezdrowa konkurencja sprawia przy tym, że wygrywający mają iluzoryczne poczucie wyższości ${ }^{42}$. Autorzy dokumentu piszą, że lęk przed porażką egzaminacyjną prowadzi

${ }^{34}$ E. Smith, Analysing Underachievement in the School, London 2005, s. 26.

35 Tamże.

36 Tamże.

37 N.E. Sapari, Questioning Meritocracy in Singapore, PRISM: USP Undergraduate Journal, 2013, 5, 1, s. 22, https://uspprism.files.wordpress.com/2015/06/ 3-questioning_meritocracy_ elysa.pdf $\backsim$ s. 22.

$38 \mathrm{~J}$. Kenway, A. Koh, The elite school as "cognitive machine" and "social paradise": Developing Transnational capital for national "field of power", Journal of Sociology, 2013, 49, 2-3, s. 286.

39 Singapure's Primary Schools Ranked by Academic Excellence, [w:] Kiasu Parents, http:// www.kiasuparents.com/kiasu/content/singapore-primary-schools-ranked-academicexcellence

${ }^{40}$ Dokument Education for Creativity and Equality: Agenda for Transformation, Singapore Democratic Party, bez daty i miejsca wydania (jednakże należy założyć, że przygotowany został w 2014 roku, ponieważ odwołuje się do dokumentów z roku 2013), s. 3.

41 Tamże, s. 11.

42 Tamże, s. 50. 
młodych Singapurczyków do depresji i z roku na rok coraz większa ich liczba korzysta $\mathrm{z}$ pomocy psychiatrów ${ }^{43}$. Z kolei autor jednego z blogów w tekście porównującym dwie najbardziej elitarne singapurskie szkoły średnie: Raffles Institute i Hwa Chong Institution - stwierdził krytycznie, iż w świadomości społecznej funkcjonują na temat absolwentów tych placówek pewne stereotypy, których istotą jest założenie, że osoby uzyskujące dobre wyniki $\mathrm{w}$ testach jednocześnie reprezentują wysoki poziom moralny i prawidłowe zachowania społeczne. Uważa on, że selekcja do tych elitarnych szkół wyłania co prawda osoby o największym potencjale intelektualnym, ale nie jest to równoznaczne z posiadaniem przez nie wysokiego morale czy dobrego charakteru ${ }^{44}$.

Trzeba dodać, że z kolei w Stanach Zjednoczonych wyniki testów na poziomie amerykańskiej szkoły średniej są na przykład silnie skorelowane z pochodzeniem społecznym uczniów ${ }^{45}$. Niektórzy amerykańscy krytycy testów twierdzą, że „mierzą [one] je d y n i e status społeczno-ekonomiczny rodzin, z których wywodzą się uczniowie" 46 . Konstrukcja testów nie do końca odpowiada przy tym logice realizowanego programu szkolnego, lecz w dużej mierze odzwierciedla logikę myślenia osób pochodzących z wyższych klas społecznych ${ }^{47}$. Traktuje się w tym kontekście testy, szczególnie te decydujące o przyszłej karierze, jako formę "regulowanego elitaryzmu” 48 . Ponadto, cała procedura przygotowania i przeprowadzania testów jest kontrolowana przez biurokrację państwową lub inne biurokratyczne agendy, które ona uprawomocnia. Wszelkie zmiany i decyzje w tym zakresie są narzucane odgórnie, a nauczyciele i uczniowie nie mają w tym zakresie żadnego wpływu ${ }^{49}$.

Z zupełnie innej, choć przywoływanej już na wstępie tego tekstu perspektywy koncentracja na testach poddawana jest przez władze elitarnych szkół brytyjskich na poziomie średnim, typu Eton College czy St. Paul's School. Uważa się, że system klasyfikowania szkół ze względu na wyniki egzaminów testowych jest dla tych szkół wręcz dyskryminujący, bowiem

43 Tamże, s. 30.

${ }^{44}$ Blog: Neurotic Ramblings of Singaporean Couple, post: Raffles Institution (RI) vs Hwa Chong Institution (HCI), 30 May 2013, http://neurotic-ramblings-sg.blogspot.com/2013/05/ raffles-institution-ri-vs-hwa-chong.html

${ }^{45}$ R. Zwick, The Role of Admissions Test Scores, Socioeconomic Status, and High School Grades in Predicting College Achievement, Pensamiento Educativo. Revista de Investicgatcion Educational Latinoamericana, 2010, 49, 2, s. 25.

46 Tamże, s. 24.

47 Tamże, s. 25.

$48 \mathrm{~W}$. Au, Unequal by Design. High-Stakes Testing and the Standarization of Inequality, New York and London 2009, s. 139.

49 Tamże, s. 91. 
ich celem jest wszechstronne kształcenie młodego człowieka oraz wspomaganie jego rozwoju w okresie krystalizacji osobowości, a nie tylko przygotowanie do testów. Twierdzi się, że program kształcenia i program wychowawczy najlepszych szkół średnich wykracza daleko poza wymagania standaryzowanych testów. W trakcie konferencji szkół elitarnych w 2008 roku, ich dyrektorzy podkreślili, że rankingi, których istotą są wyłącznie wyniki nauczania (zredukowane do wyników testów), powodują, iż poddane presji osiągnięć egzaminacyjnych szkoły dostosowują swoje kształcenie do określonych w nich wymagań, rezygnując z zajęć muzycznych, sportowych, czy teatralnych (i innych), które kształtują charakter i sposób myślenia ${ }^{50}$. Dyrektorzy sprzeciwili się tyranii rankingów, podporządkowanych wynikom egzaminów na poziomie A-level ${ }^{51}$. Można w tym miejscu przytoczyć słowa wieloletniego (i aktualnego) dyrektora Eton (i jego absolwenta), który stwierdził: „Mierzenie wyłącznie tego, co jest łatwe do zmierzenia, tak jak to ma miejsce podczas egzaminów, może prowadzić do błędnych wniosków. Istnieje niebezpieczeństwo, że mierzalne części [wykształcenia] staną się ważniejsze niż całość"52. Jego zdaniem, absolutyzacja wyników egzaminów prowadzi do zaniedbania kształcenia zarówno w sferze twórczości, jak i postaw obywatelskich. Odwołując się do poglądów Johna Miltona, stwierdził on, iż celem edukacji jest kształtowanie ludzi „kompetentnych, sprawiedliwych i wspaniałomyślnych" i o ile w trakcie egzaminów ten pierwszy element może być oszacowany, to "gdzie w testach egzaminacyjnych jest miejsce dla sprawiedliwości i wspaniałomyślności?" 53 W konkluzji dyrektor Eton podsumował: „trzymajmy się stabilnych akademickich standardów i doceniajmy młodych ludzi za ich osiągnięcia, jednakże nie mylmy sukcesów $\mathrm{w}$ rankingach z dobrym wykształceniem" 54 . Tenże sam dyrektor uwypuklił pewien paradoks testów „atomizujących” osiągnięcia uczniów, które „rozdrabniają przedmiot nauczania na małe mierzalne cząstki” 55 . Paradoks ten związany jest $\mathrm{z}$ faktem, iż uczniowie takich szkół jak Eton zmuszani

${ }^{50}$ Bez autora, Eton leads private schools in boycott of league tables, Times Education Supplements, 5 , July 2002, s. 4 .

51 A. Lipsett, Eton and St Paul's heads boycott independent schools' league tables, „The Guardian", 29 April 2008, http://www.theguardian.com/education/2008/apr/29/publicschools. schools

52 T. Little, Exams aren't everything, says Eton headmaster, „Radiotimes”, 13 August 2014, http://www.radiotimes.com/news/2014-08-13/exams-arent-everything-says-eton-

headmaster

53 Tamże.

54 Tamże.

55 Por. G. Paton, Bright pupils "agonising" over simple questions, says Eton head, http://www. telegraph.co.uk/education/educationnews/4938107/Bright-pupils-agonising-over-simple-qu estions-says-Eton-head.html 
w swoich klasach do samodzielnego myślenia, dają $\mathrm{w}$ testach bardzo inteligentne odpowiedzi na pytania, przez co wychodzą w swoich rozwiązaniach poza gotowe formuły, w których test się mieści (i nie otrzymują żadnych punktów za swoje nadzwyczajne odpowiedzi) ${ }^{56}$.

Również i w moich badaniach jakościowych, przeprowadzonych w elitarnych szkołach średnich wśród uczniów (i absolwentów) w Polsce, okazało się, że już w klasie pierwszej istotą kształcenia jest przygotowanie do maturalnych egzaminów testowych, które będą miały miejsce pod koniec klasy trzeciej ${ }^{57}$. Świadczą o tym następujące wypowiedzi uczniów:

Caty czas jest nacisk na to, że tak będzie na maturze i tak mamy się uczyć. U nas sprawdziany wygladaja tak, że dostajemy cztery kartki zadań z matur. (MARIA)

Rozmawialiśmy między soba czasami, czy warto to robić, czy czasami nie płacimy za to zbyt dużej ceny. Mamy czasami takie melancholijne dni, kiedy myśli się, że ma się już wszystkiego dosyć $i$ chciatoby się spokojnie przejść przez liceum. Ale to sq tylko okresy. Wtącza się w końcu ta ambicja u czlowieka, że już chce na site coś zrobić i pokazać się. Wtedy mijają te smutki. Do testów maturalnych [szkoła nas przygotuje - uzup. AG-M] na pewno. Często się tak zdarza na różnych przedmiotach, że wypetniamy testy, $i$ coś czasami może się nie zgadzać, ale mamy te wiedzę, że tak jest w kluczu na maturze i tak mamy robić. Przygotowuja nas do tych testów. Mamy komunikaty od nauczycieli, że nie ma co wnikać w pewne zagadnienia, bo trzeba to robić tak, żeby być dobrze ocenionym na maturze. (KAROL)

W czasie dyskusji, które toczymy na lekcji, nauczyciele sa otwarci na różne nasze punkty widzenia, podejmuja z nami dyskusję. Ale jeśli chodzi o przygotowanie się do egzaminów, to jest wstrzelanie się w jedna interpretacje, to jest najtrudniejsze, takie jest oczekiwanie, że musimy zgadzać się z tym, co egzaminator proponuje, żeby dobrze zdać egzamin. (KAMIL)

Nie mam watpliwości co do tego (że szkoła przygotuje mnie dobrze do matur). Od rozpoczęcia roku w pierwszej klasie ciagle styszymy o maturze. My już robimy mature podstawowa, a od drugiej klasy będziemy robić rozszerzona już (...) To jest kwestia wyćwiczenia (...) Wcią̇ ćwiczymy zdawanie matury. (KLAUDIA)

56 Tamże.

57 Cytowane tu fragmenty wypowiedzi uczniów i absolwentów elitarnych polskich liceów pochodzą z wywiadów przeprowadzonych w ramach grantu NCN nr NN 106112738 - Elitarne szkolnictwo średnie we wspótczesnej Europie. Studium z socjologii edukacji i pedagogiki porównawczej. Metodologia badań została opisana w książce: A. Gromkowska-Melosik, Elitarne szkolnictwo średnie. Między reprodukcją społeczno-kulturowa a ruchliwością konkurencyjna, Poznań 2015, s. 275-317. 
Mamy bardzo dużo próbnych testów. Mamy ciąle powtórki (...) (KONSTANCJA)

Bardzo często robimy zadania maturalne. Niekiedy nasze sprawdziany składaja się tylko $z$ testów maturalnych. $Z$ niektórych przedmiotów będziemy w drugiej klasie pisali regularnie próbne matury. (KLAUDIA)

W krytyczny sposób podejmuje ten problem KINGA na przykładzie jednego z przedmiotów:

Na przykład na angielskim nie podoba mi się to, że jesteśmy przygotowywani za bardzo pod maturę, bo nie oszukujmy się, jezzyk jest mi bardziej potrzebny, żeby sie nim postugiwać, a nie żeby zdać tę maturę, bo jeśli będe się nim postugiwać, to ja tę mature zdam. Ciagłe stukanie zadan maturalnych zamiast praktycznej strony czy dyskusji też nie jest dobre. Trochę za bardzo to wszystko jest pod maturę. (...) Skupienie się na testach to oczywiście spowoduje, że się napisze dobrze maturę, ale na ile to będzie wyuczone, a na ile to będzie rzetelna wiedza, to już jest inna sprawa. (KINGA)

Dodam, że uczestniczący $\mathrm{w}$ moich badaniach uczniowie polscy mają świadomość dostosowywania procesu nauczania do wymogów testów maturalnych. Często również zdają sobie sprawę, iż głównym celem kształcenia jest przygotowanie ich do doskonałego rozwiązywania testów. Wiedzą o ograniczeniach zadań testowych oraz przypadkach ich błędnej konstrukcji, są świadomi braku logiki w formułowaniu pytań, a nawet istnienia błędnych odpowiedzi czy, wreszcie, nieuwzględniania wszystkich możliwych rozwiązań. Wszystko to powoduje, że przynajmniej do pewnego stopnia stają się oni krytykami systemu testowego, którego kulminacyjnym punktem jest egzamin maturalny (dawno utracił on, jak się wydaje, status egzaminu dojrzałości). Z drugiej strony, orientacja na osiągnięcie sukcesu powoduje, że uczniowie wchodzą bez żadnych problemów w rolę konformistycznych uczestników systemu. Tak więc, „rozwijają oni świadomość samych siebie jako członków klasy społecznej, która może i powinna działać w swoim własnym interesie" 58 . Ujawnia się to $w$ wielu, nie cytowanych tutaj, ich wypowiedziach (pamiętajmy, że sformułowali je uczniowie pierwszej klasy liceum, którzy do matury przystępować będą dopiero za dwa lata).

Trudno także nie przywołać bardzo krytycznych uwag wobec polskiego, opartego na testach, systemu egzaminów zewnętrznych w oświacie, sformu-

58 Por. J. Anyon, Social class, school knowledge, and the hidden curriculum: Retheorizing reproduction [w:] Ideology, curriculum, and the new sociology of education, red. L. Weis, C. McCarthy, G. Dimitriadis, New York 2006, s. 41. 
łowanych w Raporcie Naczelnej Izby Kontroli w lutym 2015 roku. I tak, stwierdzono tam między innymi: "przyjęty sposób przygotowania testów nie był w pełni rzetelny", "po próbnym testowaniu dokonano zmian w zadaniach”, jednakże „nie poddawano ich ponownej standardyzacji”. Trudno przejść do porządku dziennego nad następnym zarzutem: „Niepokojącym zjawiskiem, w badanym okresie, była duża liczba prac egzaminacyjnych, których weryfikacja (na wniosek zdających) prowadziła do zmiany wyniku egzaminów oraz wymiany świadectw (2,6 tys., tj. 26\%). Nie sprawdzano jednak ponownie wszystkich prac ocenionych przez egzaminatora, który popełnił błąd. Oznacza to słabość mechanizmów kontrolnych". Ponadto, „CKE (Centralna Komisja Egzaminacyjna) nie wdrożyła jednolitych zasad wglądu do prac egzaminacyjnych, co powodowało nierówne traktowanie zdających. (...) Zdających nie informowano ponadto o możliwości ponownego sprawdzenia pracy egzaminacyjnej i ewentualnej zmianie jej wyniku". Niezwykle istotny jest kolejny zarzut: „Szkoły przeprowadzały analizę wyników egzaminów zewnętrznych, jednakże ograniczano się przede wszystkim do badania ilościowego danych egzaminacyjnych (m.in. średnich wyników, zdawalności egzaminów i trudności zadań). Nie uwzględniano wpływu czynników indywidualnych, środowiskowych oraz pedagogicznych (zależnych od szkoły) na osiągnięcia uczniów" ${ }^{\prime 59}$.

Należy dodać, że niezależnie od wszelkiej krytyki, owa - jak to ujmują M.S. Moses, M.J. Nanna - „kultura testowania”60 jest w coraz większym stopniu akceptowana przez społeczeństwo ${ }^{61}$. Jak pisze krytycznie P. Sacks:

Niestety, opinia publiczna w przeważającej mierze akceptuje uprawomocnienie tego narzędzia merytokracji, wierząc, że egzaminy są odpowiednim predyktorem sukcesu jednostki i dobrą miarą sukcesu naszych szkół62.

Wierzy się też, że standaryzowane testy sprawiają, iż proces nauczania jest bardziej „konkretny”, że motywuje uczniów do bardziej wytężonej zorientowanej na konkretny cel - pracy oraz że rezultaty testów mierzą osiągnięcia w sposób obiektywny63. Jak napisano we wstępie do książki Obrona standaryzowanych testów:

59 NIK. Informacja o wynikach kontroli. System egzaminów zewnętrznych w oświacie, Warszawa 6.02. 2015 roku, https://www.nik.gov.pl/plik/id,8629,vp,10737.pdf, s. 7.

${ }^{60}$ M.S. Moses, M.J. Nanna, The Testing Culture, s. 55.

${ }^{61}$ Por. też teksty naukowców broniących standardyzowanych testów, zawartych w książce pod redakcją R.P. Phelpsa, Defending Standardized Testing, New York 2005.

62 P. Sacks, Standarized Minds, s. 2.

${ }^{63}$ R.P. Phelps, Kill the Messenger, s. 17. 
Standaryzowane testy mogą przynieść przynajmniej trzy korzyści: lepszą diagnozę (silnych i słabych stron uczniów); lepszą (...) selekcję (w sferze przyjmowania do koledżów, przyznawania stypendiów oraz zatrudnienia) oraz (...) poprawę wyników nauczania ${ }^{64}$.

Warto przytoczyć w tym kontekście, znakomicie pasujące do powszechnej akceptacji znaczenia testów, słowa J.W. Meyera:

Jeżeli edukacja [można zamienić na „testologia” - AG-M] stanowi mit w społeczeństwie współczesnym, to jest to mit potężny. Efekt mitu nie polega na tym, że jednostki wierzą w niego, lecz na tym, że każdy wie, że inni „wiedzą”, i w ten sposób (...) mity stają się prawdą ${ }^{65}$.

\section{BIBLIOGRAFIA}

Anyon J., Social class, school knowledge, and the hidden curriculum: Retheorizing reproduction [w:] Ideology, curriculum, and the new sociology of education, red. L. Weis, C. McCarthy, G. Dimitriadis, New York 2006.

$\mathrm{Au}$ W., Unequal by Design. High-Stakes Testing and the Standarization of Inequality, New York and London 2009.

Au W., Hiding behind high-stakes testing: Meritocracy, objectivity and inequality in U.S. education, Education Journal: Comparative Perspectives, 2013, 12, 2.

Dokument Education for Creativity and Equality: Agenda for Transformation, Singapore Democratic Party.

Eton leads private schools in boycott of league tables, Times Education Supplements, 5, July 2002.

Gromkowska-Melosik A., Elitarne szkolnictwo średnie. Między reprodukcja społecznokulturową a ruchliwością konkurencyjną, Poznań 2015.

Harris P., Smith B.M., Harris J.J., The Myths of Standarized Tests. Why They Don't Tell You What You Think They Do, Lanham - Boudler - New York - Toronto - Plymouth 2011.

Kenway J., Koh A., The elite school as "cognitive machine" and "social paradise": Developing Transnational capital for national "field of power", Journal of Sociology, 2013, 49, 2-3.

Kirkpatrick R., Zang Y., The Negative Influences of Exam-Oriented Education on Chinese High School Students: Backwash from Clasroom to Child, Language Testing in Asia, 2011, 1, 3.

Lipsett A., Eton and St Paul's heads boycott independent schools' league tables, "The Guardian", 29 April 2008, http://www.theguardian.com/education/2008/apr/29/pub licschools.schools

Little T., Exams aren't everything, says Eton headmaster, „Radiotimes”, 13 August 2014, http:/ / www.radiotimes.com/news/2014-08-13/exams-arent-everything-says-etonheadmaster

Melosik Z., Kultura popularna i tożsamość młodzieży. W niewoli władzy i wolności, Kraków 2013.

${ }^{64}$ Por. Introduction, [w:] Defending Standardized, XV.

65 Tamże, s. 75. 
Moses M.S., Nanna M.J., The Testing Culture and the Persistence of High Stakes Testing Reforms, Education and Culture, 2007, 23, 1.

Neurotic Ramblings of Singaporean Couple, post: Raffles Institution (RI) vs Hwa Chong Institution (HCI), 30 May 2013, http://neurotic-ramblings-sg.blogspot.com/2013/ 05/raffles-institution-ri-vs-hwa-chong.html

NIK. Informacja o wynikach kontroli. System egzaminów zewnętrznych w oświacie, Warszawa 6.02.2015 roku, https:/ / www.nik.gov.pl/plik/id,8629,vp,10737.pdf, s. 7.

Paton G., Bright pupils "agonising” over simple questions, says Eton head, http://www. telegraph.co.uk/education/educationnews/4938107/Bright-pupils-agonising-oversimple-questions-says-Eton-head.html

Phelps R.P. (red.), Defending Standardized Testing, New York 2005.

Phelps R.P., Kill the Messenger. The War on Standardized Testing, New Jersey 2009.

Ravitch D., The Death and Life of the Great American School System. How Testing and Choice Are Undermining Education, New York 2010.

Sacks P., Standardized minds: The High Price of America's Testing Culture and what We Can Do to Change It, New York 1999.

Sapari N.E., Questioning Meritocracy in Singapore, PRISM: USP Undergraduate Journal, 2013, 5, 1, s. 22, https://uspprism.files.wordpress.com/2015/06/ 3-questioning meritocracy_elysa.pdf $\backsim$ s. 22.

Shohamy E., The Power of Tests. A Critical Perspective on the Uses of Language Tests, Harlow 2001.

Singapure's Primary Schools Ranked by Academic Excellence, [w:] Kiasu Parents, http:// www.kiasuparents.com/kiasu/content/singapore-primary-schools-rankedacademic-excellence

Smith E., Analysing Underachievement in the School, London 2005.

Yoneyama S., The Japanese High School: Silence and Resistance, London 1999.

Zwick R., The Role of Admissions Test Scores, Socioeconomic Status, and High School Grades in Predicting College Achievement, Pensamiento Educativo. Revista de Investicgatcion Educational Latinoamericana, 2010, 49, 2. 